\title{
MYCOREMEDIATION OF CONGO RED DYE BY FILAMENTOUS FUNGI
}

\author{
Sourav Bhattacharya*, Arijit Das, Mangai. G, Vignesh. K, Sangeetha. J
}

Department of Microbiology, Genohelix Biolabs, Jain University 127/ 3, Bull Temple Road, Chamarajpet, Bangalore - 560019, Karnataka, India.

Submitted: September 09, 2010; Approved: May 16, 2011.

\begin{abstract}
Azo, anthroquinone and triphenylmethane dyes are the major classes of synthetic colourants, which are difficult to degrade and have received considerable attention. Congo red, a diazo dye, is considered as a xenobiotic compound, and is recalcitrant to biodegradative processes. Nevertheless, during the last few years it has been demonstrated that several fungi, under certain environmental conditions, are able to transfer azo dyes to non toxic products using laccases. The aim of this work was to study the factors influencing mycoremediation of Congo red. Several basidiomycetes and deuteromycetes species were tested for the decolourisation of Congo red $(0.05 \mathrm{~g} / \mathrm{l})$ in a semi synthetic broth at static and shaking conditions. Poor decolourisation was observed when the dye acted as the sole source of nitrogen, whereas semi synthetic broth supplemented with fertilizer resulted in better decolourisation. Decolourisation of Congo red was checked in the presence of salts of heavy metals such as mercuric chloride, lead acetate and zinc sulphate. Decolourisation parameters such as temperature, $\mathrm{pH}$, and $\mathrm{rpm}$ were optimized and the decolourisation obtained at optimized conditions varied between $29.25-97.28 \%$ at static condition and $82.1-100 \%$ at shaking condition. Sodium dodecyl sulphate polyacrylamide gel electrophoretic analysis revealed bands with molecular weights ranging between 66.5 to $71 \mathrm{kDa}$, a characteristic of the fungal laccases. High efficiency decolourisation of Congo red makes these fungal forms a promising choice in biological treatment of waste water containing Congo red.
\end{abstract}

Key words: Azo Dyes; Congo red; Laccases; Mycoremediation.

\section{INTRODUCTION}

Dyes are usually aromatic and heterocyclic compounds and are often recalcitrant, some of them being toxic and even carcinogenic (40). They include a broad spectrum of different chemical structures, primarily based on substituted aromatic and heterocyclic groups such as the aromatic amine $\left(\mathrm{C}_{6} \mathrm{H}_{5}-\right.$
$\left.\mathrm{NH}_{2}\right)$, which is a suspected carcinogen, phenyl $\left(\mathrm{C}_{6} \mathrm{H}_{5^{-}}-\mathrm{CH}_{2}\right)$ and naphthyl $\left(\mathrm{NO}_{2}-\mathrm{OH}\right)$. Common to them is their ability to absorb light in the visible region (30).

Dyes are released into the environment in industrial effluents from two major sources, the textile and the dyestuff industries $(20,22)$. A necessary criterion for the use of these dyes is that they must be highly stable in light and during

\footnotetext{
*Corresponding Author. Mailing address: Department of Microbiology, Genohelix Biolabs, Jain University, 127/3, Bull Temple Road, Chamarajpet, Bangalore-560019, India.; Tel.: +9198869 19383.; Email: sourav3011@rediffmail.com
} 
washing. They must also be resistant to microbial attack. Therefore, they are not readily degradable and are typically not removed from water by conventional wastewater treatment systems $(2,27)$. While most dyes are not particularly toxic, still a large number of them are considered to be a pollution problem $(6,22)$.

Azo dyes are the largest class of dyes with the greatest variety of colours $(2,18,22)$. They also exhibit great structural variety, so, as a group, they are not uniformly susceptible to microbial attack (22). Azo dyes are not typically degraded under aerobic conditions (2, 24, 25, 43). However, under anaerobic conditions, the azo linkage can be reduced to form aromatic amines which are colourless but which can be toxic and carcinogenic $(22,43)$.

Direct dyes lack fastness during washing and so they are popular for items which are less likely to require fastness during washing like paper. A direct diazo dye commonly used in the paper industry is Congo red, which is intended primarily for the colouration of paper products. It is a recalcitrant and a known carcinogen because of the presence of the aromatic amine group $(9,30,39)$. Congo red is the sodium salt of benzidinediazo-bis-1-naphthylamine-4-sulfonic acid (formula: $\mathrm{C}_{32} \mathrm{H}_{22} \mathrm{~N}_{6} \mathrm{Na}_{2} \mathrm{O}_{6} \mathrm{~S}_{2}$; molecular weight: $696.66 \mathrm{~g} / \mathrm{mol}$ ). It is a secondary diazo dye.

Removal of dyes from textile waste effluents has been carried out by physical, chemical and biological methods, such as flocculation, membrane filtration, electrochemical techniques, ozonation, coagulation, adsorption and fungal discolouration (15). Biological processes have potential to convert or degrade the pollutant into water, carbon dioxide and various salts of inorganic nature.

In recent years, there has been an intensive research on fungal decolourisation of dye wastewaters. It is turning into a promising alternative to replace or supplement present treatment processes (31). The degradation of dyestuffs by fungi has been carried out with either whole cultures or crude enzyme preparation of extracellular ligninolytic enzymes.
Decolourisation of azo, anthraquinonic, heterocyclic, triphenylmethane and polymeric dyes and their partial mineralisation by enzymatic and non-enzymatic systems of these fungi have been reported $(14,36)$. Several ascomycetes and basidimycetes fungi have been reported to produce the lignin-degrading enzymes laccase, Lignin Peroxidases (LiP) and Manganese Peroxidases (MnP), or at least one of these enzymes (13). The lignin-degrading system of these fungi is able to degrade a wide range of structurally diverse organic pollutants (8). Although azo dyes are generally considered to be nonbiodegradable under aerobic conditions, we hypothesized that the nonspecific nature of the lignindegrading system could reasonably be expected to be effective in degrading these dyes.

In this report, we demonstrate the aerobic biodegradation abilities of six fungal species, Aspergillus niger, Aspergillus flavus, Aspergillus oryzae, Penicillium chrysogenum, Cladosporium rubrum and Pleurotus ostreatus for the azo dye Congo red and the factors influencing the degradation.

\section{MATERIALS AND METHODS}

\section{Microorganisms Used}

The soil and sludge samples were aseptically collected in sterile zip- lock covers from the vicinity of a paper processing industry located in Bangalore city. The isolation of the pure fungal forms was carried out using serial dilution and agar plate techniques. The isolates were identified based on macroscopic and microscopic characteristics. All the fungal isolates were deposited in the Department of Microbiology, Genohelix Biolabs, Jain University, Bangalore, India. The filamentous fungal forms were grown and preserved on Sabouraud dextrose agar (SDA) and Pleurotus ostreatus was grown and maintained on Malt extract agar slants. All the isolates were incubated at $28^{\circ} \mathrm{C}$ for 6 days before use. Subcultures were routinely made every 30 days. Each of the tests in the determination of the degradation activity was 
conducted in triplicates.

\section{Dyes and Chemicals}

Congo red was obtained from Nice Chemicals Limited (Bangalore, India) and other fine chemicals were from SRL Chemicals, India. All the chemicals used were of the highest purity available and of analytical grade. To study the potency of pure culture of fungal species for the degradation of the azo dye Congo red, semi synthetic media was used with the following composition $(\mathrm{g} / \mathrm{L})$ along with Congo red of 0.050 $\mathrm{g} / \mathrm{L}, \quad\left(\mathrm{NH}_{4}\right)_{2} \mathrm{SO}_{4}, \quad 0.28 ; \quad \mathrm{NH}_{4} \mathrm{Cl}, \quad 0.23 ; \quad \mathrm{KH}_{2} \mathrm{PO}_{4}, \quad 0.0067$; $\mathrm{MgSO} 4.7 \mathrm{H}_{2} \mathrm{O}, 0.04 ; \mathrm{CaCl}_{2} .2 \mathrm{H}_{2} \mathrm{O}, 0.022 ; \mathrm{FeCl}_{3} .6 \mathrm{H}_{2} \mathrm{O}, 0.005$; Yeast extract, $0.2 ; \mathrm{NaCl}, 0.015 ; \mathrm{NaHCO}_{3}, 1.0$ and $1 \mathrm{ml} / \mathrm{L}$ of trace element solution containing $(\mathrm{g} / \mathrm{L}) \mathrm{ZnSO} .7 \mathrm{H}_{2} \mathrm{O}, 0.01$; $\mathrm{MnCl}_{2} .4 \mathrm{H}_{2} \mathrm{O}, 0.1 ; \mathrm{CuSO}_{4} .5 \mathrm{H}_{2} \mathrm{O}, 0.392 ; \mathrm{CoCl}_{2} .6 \mathrm{H}_{2} \mathrm{O}, 0.248$; $\mathrm{NaB}_{4} \mathrm{O}_{7} .10 \mathrm{H}_{2} \mathrm{O}, 0.177$ and $\mathrm{NiCl}_{2} \cdot \mathrm{H}_{2} \mathrm{O}, 0.02$ with glucose $(1 \%$ $\mathrm{w} / \mathrm{v})$.

\section{Congo red decolourisation analysis}

A loopful of the fungal isolates were inoculated into respective tubes containing $10 \mathrm{ml}$ of physiological saline. The spore count was measured using a Neubauer chamber (Rohem, India) and adjusted to a final concentration of $10^{6}$ spores per ml. Pure cultures were established by inoculating the media with spores and tested for their ability to decolourise Congo red by spectrophotometric analysis $(12,19)$. A $1.5 \mathrm{ml}$ aliquot of the decolourised culture broth was placed in Eppendorf tubes and centrifuged at 14,000 rpm for 3 minutes. The supernatant was recovered and analyzed spectrophotometrically at a wavelength corresponding to the maximum absorbance of the dye which is $570 \mathrm{~nm}$. The uninoculated medium was used as control and the medium without dye was used as blank. Decena and Barraquio (12) expressed the efficiency of the isolates to degrade/decolourise Congo red as:

\footnotetext{
$\%$ Efficiency of degradation/decolourisation

$=[($ Initial conc. of dye - residual conc. of dye $) /$ Initial conc. of dye] $\times 100$
}

After 96 hrs of incubation with the fungal cultures some of the dye remained adsorbed to the fungal mycelia. In an attempt to solubilize any bound dye, the mycelial growths were homogenized in $10 \mathrm{ml}$ of methanol in a tissue homogenizer. The homogenate was centrifuged at 2,000 rpm for $5 \mathrm{~min}$, and the mycelial pellet was suspended in an additional $5 \mathrm{ml}$ of methanol and recentrifuged. The two resulting supernatants were combined. The absorbance of the supernatant was then determined, and the amount of dye associated with the mycelial mat was calculated (9).

\section{Dye as the sole source of nitrogen}

Nitrogen sources of the semi synthetic media such as $\left(\mathrm{NH}_{4}\right)_{2} \mathrm{SO}_{4}$ and $\mathrm{NH}_{4} \mathrm{Cl}$ were omitted and the semi synthetic media after autoclaving was cooled and $0.050 \mathrm{~g} / \mathrm{L}$ of Congo red was added and mixed well. A loopful of the fungal cultures were inoculated individually in culture tubes of two sets and incubated at static $\left(30^{\circ} \mathrm{C}\right)$ and shaking condition $(120 \mathrm{rpm}$, $30^{\circ} \mathrm{C}$ ) respectively. Decolourisation was monitored and measured every 24 hrs till 96 hrs using UV spectrophotometer at $570 \mathrm{~nm}$.

\section{Biostimulation by NPK fertilizer}

Biostimulation involves the modification of the environment to stimulate existing microorganisms capable of bioremediation. This can be done by addition of various forms of rate limiting nutrients and electron acceptor such as phosphorus, nitrogen, oxygen or carbon. To biostimulate the fungal species in this study for the Congo red degradation, the inorganic NPK fertilizer (1\%) is substituted to the nitrogen source of the liquid semi synthetic medium. Fungal forms were inoculated and the cultural conditions mentioned above were followed. Spectrophotometric analysis at $570 \mathrm{~nm}$ was conducted for checking the efficiency of degradation.

\section{Degradation in $\mathrm{CuSO}_{4}$ free medium}

The fungal enzyme laccase and associated enzymes that degrade Congo red is a copper dependent enzyme, so to check the 
degradation activity of the fungal species in a copper free environment, the semi synthetic media was prepared without the copper source $\left(\mathrm{CuSO}_{4}\right)$. Following autoclaving the tubes were cooled and $0.050 \mathrm{~g} / \mathrm{L}$ of Congo red was added and mixed well . A loopful of the fungal cultures were inoculated to the respective tubes and then incubated as mentioned above. Dye degradation was determined following the spectrophotometric analysis.

\section{Heavy metal resistance in Mycoremediation}

Heavy metals are used in the following processes, such as desizing, bleaching, dyeing and finishing, in dye and textile industries, so the waste water from these industries has the possibility to contain heavy metals in it. To check the decolourisation ability of the fungal species against heavy metal resistance, the semi synthetic medium with the nitrogen source substitution by NPK fertilizer was prepared along with each heavy metal salts: mercuric chloride, lead acetate and zinc sulphate respectively. Degradation activities were measured following the cultural conditions as mentioned above.

\section{Degradation at various $\mathbf{p H}$}

To optimize the medium condition for the best decolourisation of Congo red by the fungal species, $\mathrm{pH}$ is one of the important parameter that has to be optimized. So the semi synthetic medium with the nitrogen source was prepared having different $\mathrm{pH}$. The $\mathrm{pH}$ was varied between 4 to 8 with an increment of one unit.

\section{Degradation at various temperatures}

Temperature plays an important role in the growth of an organism, so as to optimize the temperature for the best degradation activity of the fungal species, it has been checked with three different temperatures such as $30^{\circ} \mathrm{C}, 37^{\circ} \mathrm{C}$ and $42^{\circ} \mathrm{C}$.

\section{Rpm optimization}

Rpm was optimised using the four rpm levels such as 50, 100, 150 and 200. The semi synthetic medium with the nitrogen source substitution by NPK fertilizer was prepared, autoclaved, cooled, Congo red added and then dispensed in different culture tubes. The culture tubes of four different sets were kept in four different shakers set at four different rpms such as 50,100, 150 and 200 respectively. Decolourisation was measured every 24 hrs till 96 hrs using UV spectrophotometer.

\section{Decolourisation at various concentrations}

Throughout the study, the concentration of $0.005 \%$ Congo red was used. A few other higher concentrations such as $0.05 \%$ and $0.5 \%$ were experimented in this study to know the degradation ability of the fungal species used. Cultural conditions and results of the decolourisation were determined based on the same lines as mentioned above.

\section{Partial purification and protein profile of the enzyme}

The extracellular fungal laccase, which was expected to be responsible for decolourisation of Congo red by fungal species was assayed as follows. The fungal species were grown in the semi synthetic media. Following the incubation period, the fungal growths were removed by filtration using filter paper. The filtrates were centrifuged at $12000 \mathrm{rpm}$ for $30 \mathrm{mins}$ and the supernatant was separated. Equal volume of $45 \%$ saturated ammonium sulphate solution was added to the supernatant and kept overnight at $-20^{\circ} \mathrm{C}$ for precipitation. Following precipitation, centrifugation of the supernatants resulted in the formation of pellets, which were collected and stored in phosphate buffer $(\mathrm{pH}$ 7.0). The molecular weights of the enzyme were determined using SDS-PAGE. Molecular weight markers ranging from 6.5 to $175 \mathrm{kDa}$ were used. Following electrophoresis, the gel was stained with Coomassie Brilliant Blue (s.d. Fine- Chem, Mumbai). The apparent molecular weights of the samples were determined by comparison with the mobility of the standard markers (NEW ENGLAND BioLabs, U.K.).

\section{RESULTS AND DISCUSSION}

Every production process goes with waste generation. Thus, effluents that emanate from the production process of industries, if not properly disposed, can cause serious environmental pollution, sometimes to the levels that can 
threaten human health, livestock, wildlife, aquatic lives and indeed the entire ecosystem. Of all the technologies investigated in waste cleaning, bioremediation has emerged as the most desirable approach for cleaning up many environmental pollutants. The general approaches to bioremediation are to enhance natural biodegradation by native organisms or to carry out environmental modification by applying nutrients or aeration (biostimulation), or through addition of microorganisms (bioaugmentation) (3).

The ability of microorganisms to transform a variety of chemicals has led to their use in bioremediation processes. A number of microorganisms have hence been studied to unfold their degradative abilities in remediation of pollutants. Most studies on the metabolism of organic contaminants have been performed with bacteria especially in the context of bioremediation (16). Bacteria generally are easier to culture and they grow more quickly than fungi. They are more amenable to molecular genetic manipulations. They are able to metabolise chlorinated and other organic contaminant such as oil and mineralise chemicals using them as carbon or energy source (16). Diverse fungal cultures have been investigated recently for bioremediation processes $(4,7,38)$. By virtue of their aggressive growth, greater biomass production and extensive hyphal reach in the environment, fungi have been seen to perform better than bacteria. The high surface-to-cell ratio of filamentous fungi makes them better degraders under certain niches (3).

From the soil and sludge samples analyzed, various fungal isolates obtained were identified as Aspergillus niger, Aspergillus flavus, Aspergillus oryzae, Penicillium chrysogenum, Cladosporium rubrum and Pleurotus ostreatus. A. flavus showed the highest decolourising rate for Congo red as compared with the other tested organisms. The results obtained showed that $A$. flavus cells decolourised $98.86 \%$ Congo red within 96 hrs by simultaneous biosorption and further biodegradation (Fig. 1). It was also observed that cells were red during the initial phase of growth while after $72 \mathrm{hrs}$ they regained their normal colour. This indicates that Congo red decolourisation occurs in the initial stages of growth due to biosorption of the dye inside the cell and the cells start biodegradation of Congo red in the final stages of growth. Similar results were observed with Saccharomyces cerevisiae cells (17). A. kilense cells clearly showed the high percentage of decolourisation of Congo red which is due to microbial biotransformation and not due to biosorption (42).

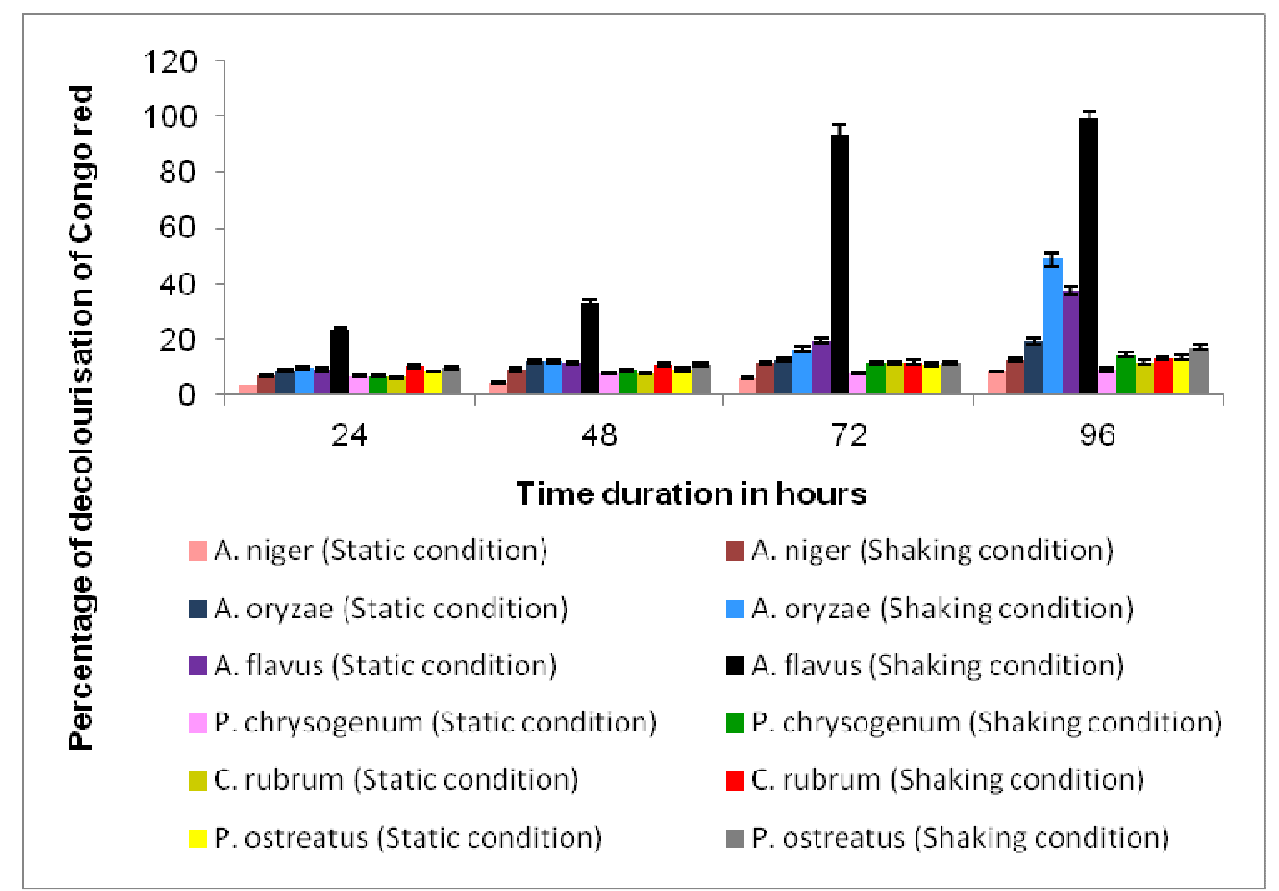

Figure 1. Congo red decolourisation pattern of the test cultures. 
The results showed that shaking generally favoured higher decolourisation and faster biodegradation of Congo red when compared to static cultures. This may be due to an increase in the mass and oxygen transfer between cells and the medium, factors that optimise the action of oxidative enzymes. This result is in line with other workers, who compared static and shake culture in decolourisation of dyes by Phanerocheate chrysosporium $(21,33)$. Literature suggests that colour removal of triphenylmethane dyes was due to soluble cytosolic enzymes and the enzyme was an NADH/NADPH- dependent oxygenase (32).

The presence of $1 \%$ glucose as the carbon source in the media starts the cell growth, the cell mass increases and causes higher decolourisation of Congo red. The potency of the pure fungal cultures in the degradation of Congo red varied between $3.60 \%$ to $24.75 \%$ under static condition and $5.76 \%$ to $39.06 \%$ under shaking condition (Fig. 2). This indicates that catabolisable carbon source like glucose accelerates the rate of decolourisation. Study of the decolourisation of reactive red 195 and reactive green 11 also revealed similar results (44). However few other workers differed from this observation and reported no decolourisation of malachite green with media supplemented with $1 \%$ glucose. They observed that presence of molasses, sucrose and urea in semi- synthetic medium showed maximum decolourisation of malachite green compared to peptone and glucose (28).

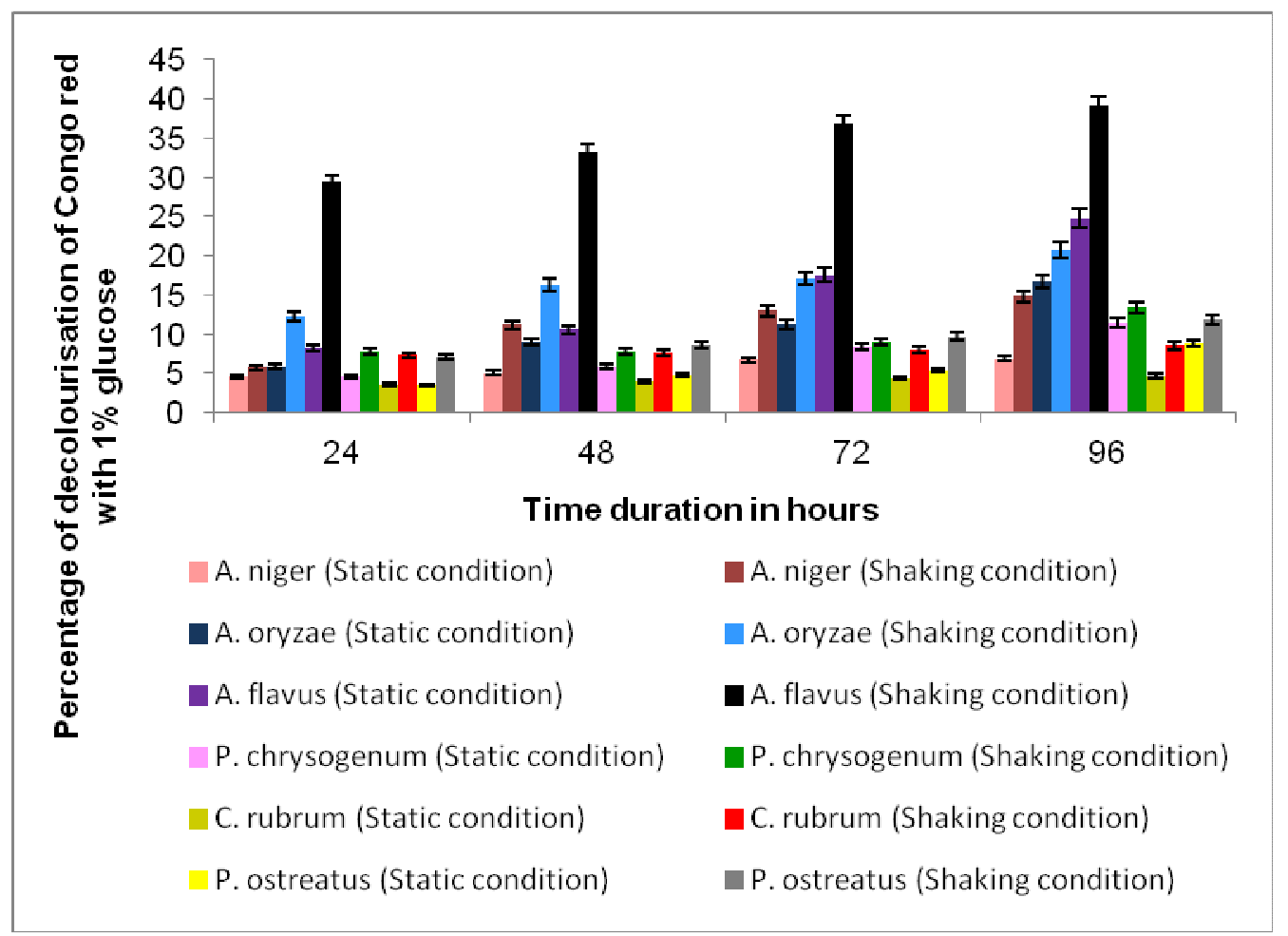

Figure 2. Congo red decolourisation pattern in media supplemented with $1 \%$ glucose.

Fig. 3 shows the decolourising activity of the fungal forms when the semi synthetic media was supplemented with biostimulating agents NPK fertilizer. Results revealed that the percentage of decolourisation of Congo red varied between
$74.91 \%$ to $93.94 \%$ (static) and $74.85 \%$ to $99.5 \%$ at shaking condition. Fertilization of the media with commonly used fertilizer meets the energy needs of the organisms as the industrial wastewaters are mostly devoid of these essential nutrients. 


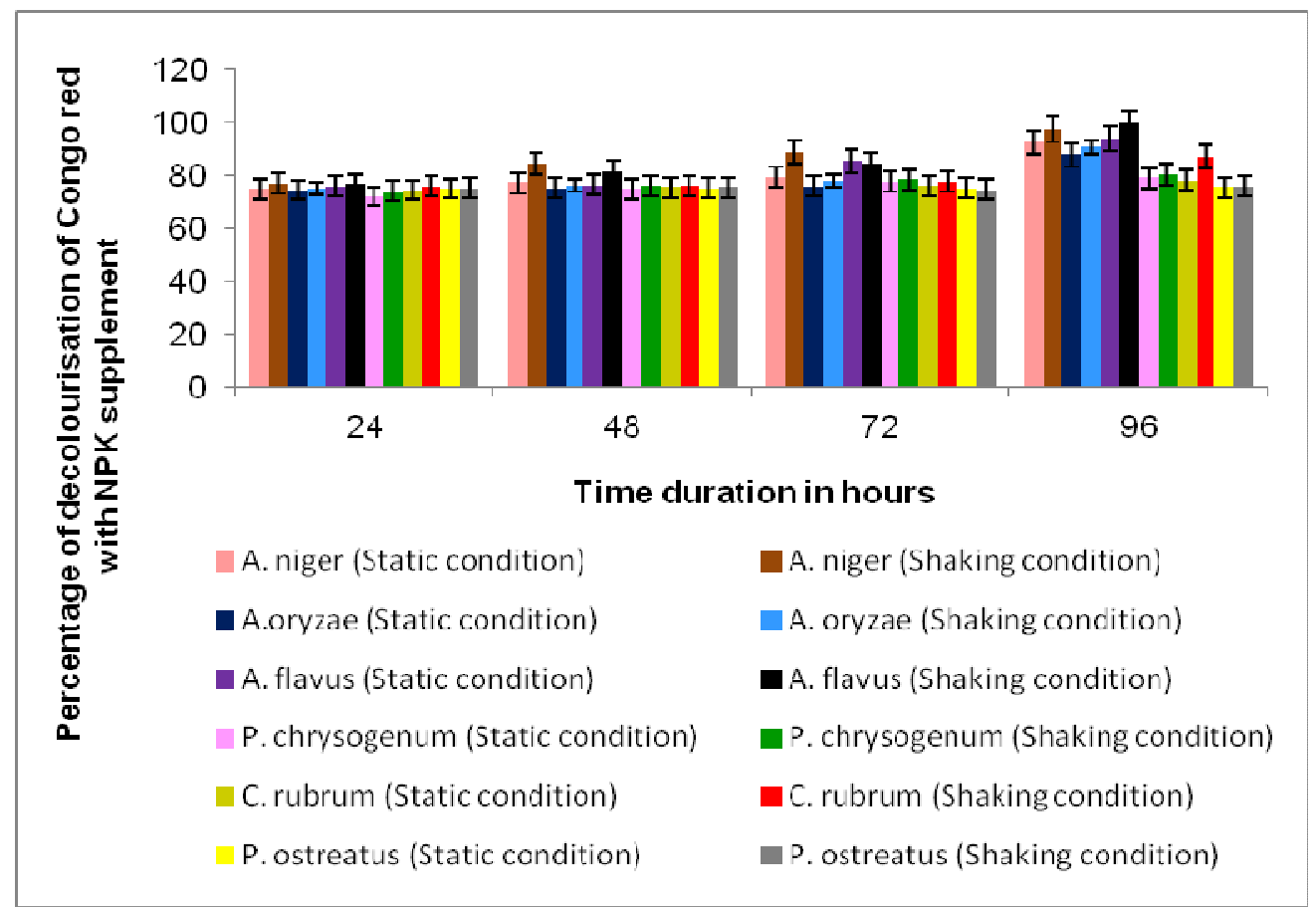

Figure 3. Congo red decolourisation pattern in media with NPK supplement.

The extracellular fungal enzyme laccase that degrades the Congo red, is a copper dependent enzyme. In the copper sulphate deficient media the percentage decolourisation varied between $2.64 \%$ to $29.93 \%$ (static) and $3.55 \%$ to $89.64 \%$ (shaking) (Fig. 4 ).

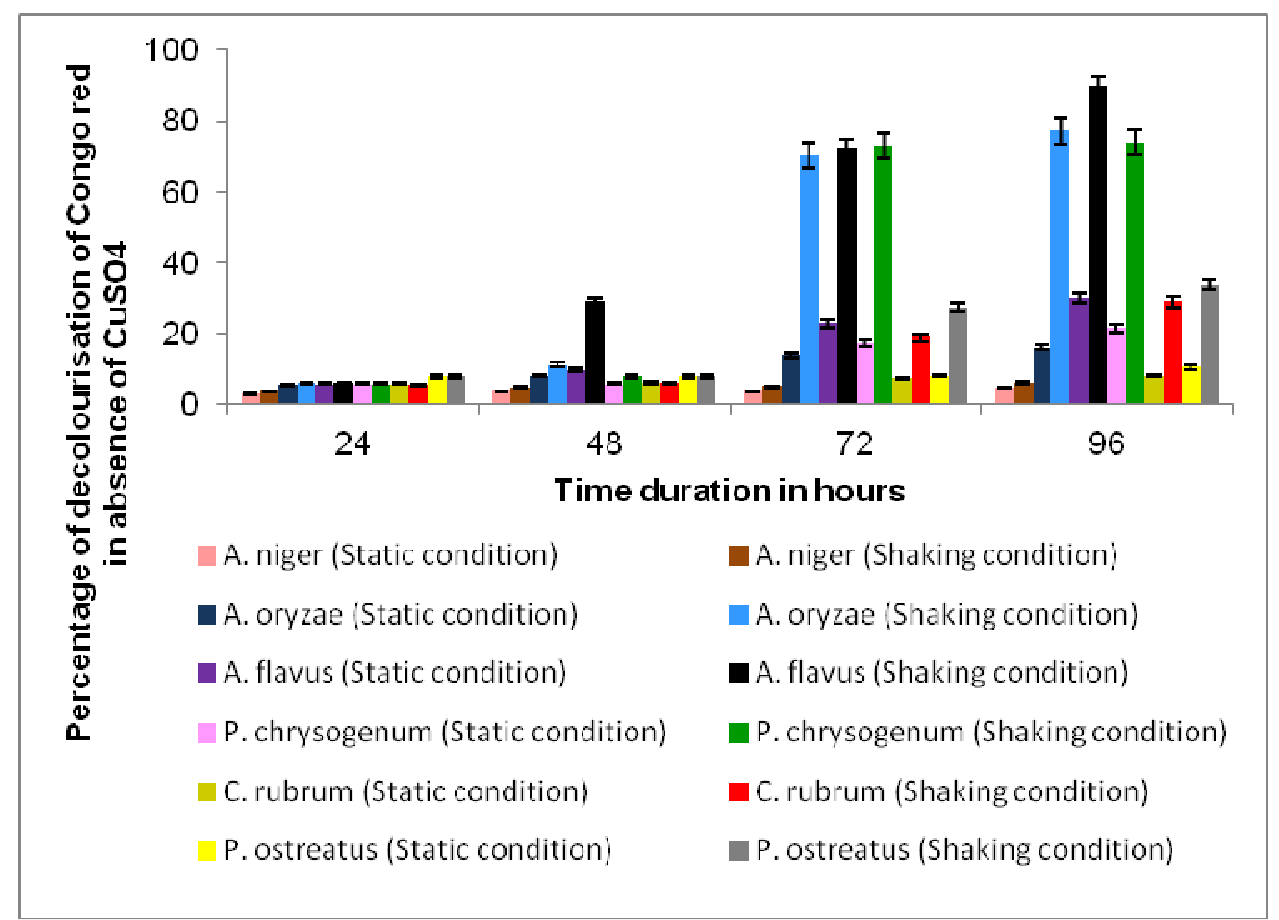

Figure 4. Congo red decolourisation pattern of the test cultures in the absence of $\mathrm{CuSO}_{4}$. 
In the presence of the heavy metals, the decolourisation was not affected to a greater magnitude, proving that the degradative enzyme machinery of the fungal isolates is not affected by their presence. Similarly, previous studies reported that two subtropical strains of basidiomycetes were capable of dye decolourisation in the presence of $0.25 \mathrm{mM}$ of salts of zinc, cadmium and nickel (29).

Every microorganism has a minimal, a maximal and an optimal $\mathrm{pH}$ for growth and metabolism. Microbial cells are significantly affected by the $\mathrm{pH}$ of their immediate environment because they apparently have no mechanism for adjusting their internal $\mathrm{pH}$. Thus studying the effect of the media $\mathrm{pH}$ on the decolourisation activities of our test organisms was an important criterion of this paper. In order to check the effect of initial $\mathrm{pH}$ on the efficiency of microorganisms to reduce the colour intensity of Congo red: $\mathrm{pH}$ was varied within the range of 4-10. Results indicated that the neutral medium condition facilitated best decolourisation. Fig. 5 demonstrates the decolourisation pattern of the fungal species at neutral $\mathrm{pH}$. Previously, after $72 \mathrm{hrs}$ of incubation with $A$. niger grp, neutral $\mathrm{pH}$ was found to be most suitable for maximum decolourisation of both reactive red 195 and reactive green $11(44)$.

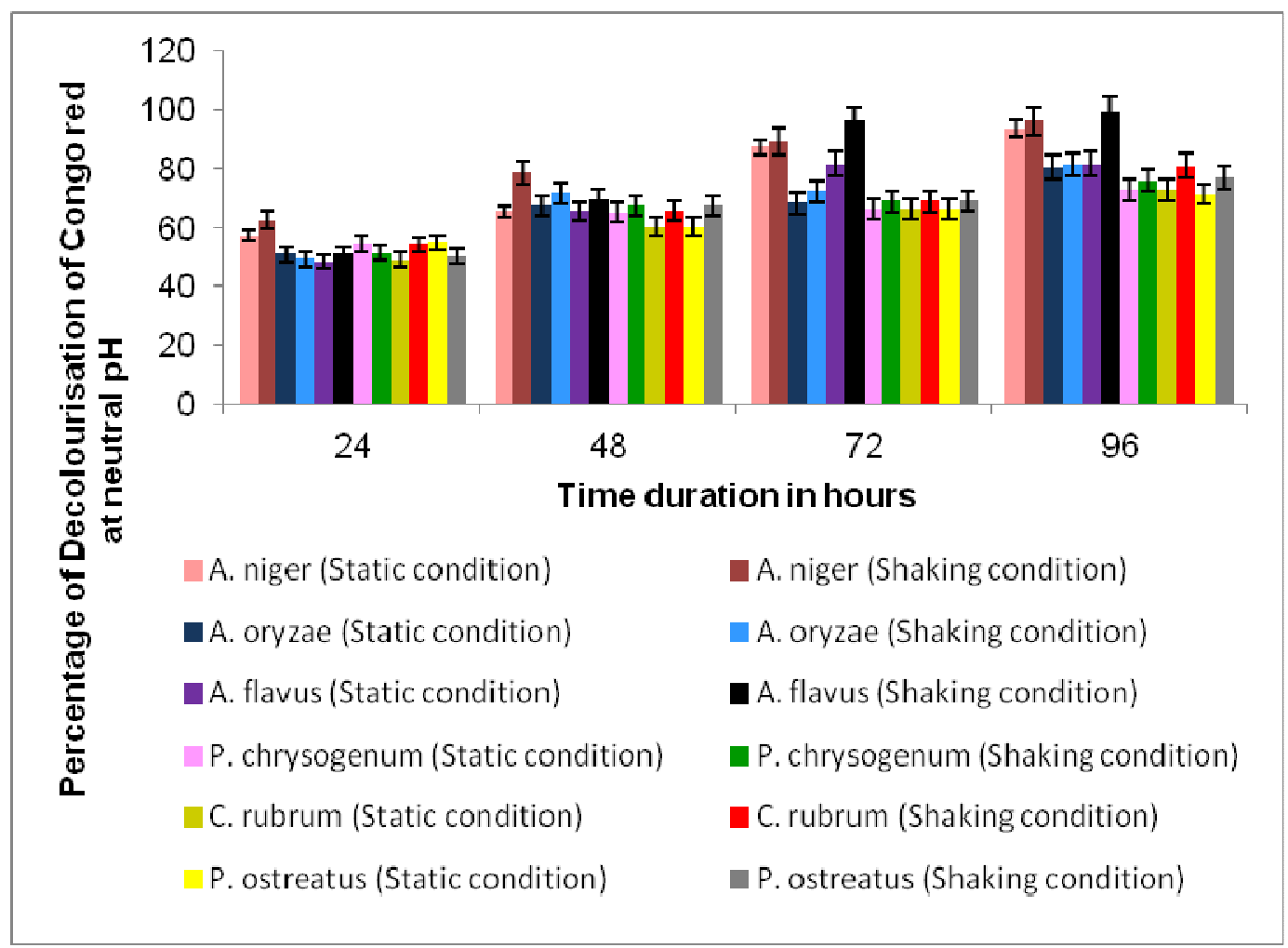

Figure 5. Congo red decolourisation pattern of the test cultures at neutral pH.

Decolourisation at $30^{\circ} \mathrm{C}$ varied between $55.34 \%$ to $79.58 \%$ at static condition and $38.17 \%$ to $98.85 \%$ at shaking condition. The efficiency of decolourisation decreases with the increase in temperature. Variation of $\mathrm{rpm}$ revealed that Congo red was decolourised at the levels of $70.62 \%$ to $99.81 \%$ at $50 \mathrm{rpm}, 29.25 \%$ to $97.28 \%$ at $100 \mathrm{rpm}, 82.10 \%$ to $100 \%$ at $150 \mathrm{rpm}$ and at $200 \mathrm{rpm}$ it varied between $69.65 \%$ to $99.42 \%$.

The percentage of decolourisation at $0.05 \mathrm{~g} / \mathrm{L}$ of Congo red 
varied between $55.34 \%$ to $99.85 \%$ at static and $82.10 \%$ to $100 \%$ at shaking condition, $0.5 \mathrm{~g} / \mathrm{L}$ of dye was decolourised to levels of $0.362 \%$ to $99.35 \%$ and $0.96 \%$ to $99.72 \%$ at static and shaking respectively. At $5 \mathrm{~g} / \mathrm{L}$ of Congo red insignificant levels of decolourisation were observed. This result is at per with the result obtained for malachite green degradation, where degradation decreased with the increase in the concentration of dye (28). The indigoid dye Indigo Carmine decolourisation by crude enzyme from Pleurotus sajor - caju at different initial concentrations $(50-500 \mu \mathrm{M})$ was studied, wherein $80 \%$ decolourisation was reported at $50 \mu \mathrm{M}$ concentration and 60 and $10 \%$ decolourisation at 250 and $500 \mu \mathrm{M}$ concentrations respectively (34).

Laccase is one of a relatively small number of proteins which retain enzymatic activity even after the SDS-PAGE procedure $(5,10,26,35)$. Molecular weights of most fungal laccase proteins fall between 43,000 and $110,000(37,41)$. The SDS-PAGE results show that the laccases involved in the decolourisation of Congo red have a molecular weight of 66,500 to 71,000 , which is in the range reported for other deuteromycetes and basidiomycetes $(25,41)$. A majority of laccases from basidiomycete fungi were reported to have molecular weights in the range of 55,000 to $72,000(37,41)$, but several isoforms of laccases from the well-studied white rot fungus Trametes versicolor were reported to be 43,000 to $66,000(25,41)$. Five isoforms of Schizophyllum commune laccases ranged in molecular weight from 36,000 to 48,000 $(11,41)$. However, it was suggested that the high molecular weight reported for some laccases might be due to incomplete dissociation of these proteins during the SDS-PAGE procedure.

A large number of researches have been carried out with bacteria that are capable of removing Congo red to a lesser extent from the contaminated site. To the best of our knowledge, this is the first report with respect to the degradation of Congo red by fungal species. Thus, it may be urged that $A$. flavus and the other fungal forms used in this study are good potential candidates for the decolourisation of
Congo red and possibly other dyes. The ability of $A$. flavus to decolourise malachite green has already been established (1). Further studies in this domain are valuable to use these microorganisms for the decolourisation of real dye wastewaters (which are complex mixtures of many dyes) and to know about the nature and fate of the degradation products.

\section{ACKNOWLEDGEMENTS}

We wish to extend our sincere gratitude to Dr. Chenraj Jain, Chairman, Jain Group of Institutions, Bangalore, India, for providing us with all the financial and laboratory facilities required for this research work.

\section{REFERENCES}

1. Ali, H.; Ahmad, W.; Haq, T. (2009). Decolourisation and degradation of malachite green by Aspergillus flavus and Alternaria solani. Afr. J. Biotechnol. 8 (8), 1574-1576.

2. Anliker, R. (1979). Ecotoxicology of dyestuffs: a joint effort by industries. Ecotoxicol. Environ. Saf. 3, 59-74.

3. Ashoka, C.; Geetha, M.S.; Sullia, S.B. (2002). Bioleaching of composite textile dye effluent using bacterial consortia. Asian J. Microbial Biotech. Environ. Sci. 4, $65-68$.

4. Aust, S.D. (1990). Degradation of environmental pollutants. Microb. Ecol. 20, 197 - 209.

5. Bao, W.; O’Malley, D.M.; Whetten, R.; Sederoff, R.R. (1993). A laccase associated with lignification in loblolly pine xylem. Science. 260, 672674.

6. Brown, D.; Hitz, H.R.; Schafer, L. (1981). The assessment of the possible inhibitory effect of dye-stuffs on aerobic wastewater bacteria: Experience with a screening test. Chemosphere. 10, 215-261.

7. Bumpus, J.A.; Aust, S.D. (1987). Biodegradation of DDT (1, 1, 1trichloro- 2, 2-bis-(4-chlorophenyl) ethane) by the white - rot fungus Phanerochaete chrysosporium. Appl. Environ. Microb. 53, 2001 - 2008.

8. Bumpus, J.A.; Aust, S.D. (1987). Biodegradation of environmental pollutants by the white rot fungus Phanerochaete chrysosporium: involvement of the lignin degrading system. Bioessays. 6, 166-170.

9. Cripps, C.; Bumpus, J.; Aust, S. (1990). Biodegradation of heterocyclic dyes by phanaerochaete chrysosporium. Appl. Environ. Microbiol. 56 (4), 1114- 1118.

10. Dass, S.B.; Desoretz, C.G.; Reddy, C.A.; Grethlein, H.E. (1995). 
Extracellular proteases produced by the wood-degrading fungus Phanerochaete chrysosporium under ligninolytic and non-ligninolytic conditions. Arch. Microbiol. 163, 254-258.

11. De Vries, O.M.H.; Kooistra, W.H.C.F.; Wessel, J.G.H. (1986). Formation of an extracellular laccase by Schizophyllum commune dikaryon. J. Gen. Microbiol. 132, 2817-2826.

12. Decena, A.L.A.; Barraquio, W.L. (2004). Congo red decolourisation by bacteria. XXXIII PSM Annual Convention and Scientific Meeting, Philippine Society for Microbiology Inc., Metro Manila, Philippines, $\mathrm{p}$. 48.

13. Eggert, C.; Temp, U.; Eriksson, K.E. (1996). Laccase- producing white rot fungus lacking lignin peroxidase and manganese peroxidase. $A C S$ Symp. Ser. 655, 130- 150.

14. Ferreira, V.S.; Magalhaes, D.B.; Kling, S.H.; da Silva, J.G.; Bon, E.P.S (2000). N-demethylation of methylene blue by lignin peroxidase from Phanerocheate chrysosporium. Applied Biochem. Biotechnol. 84, 255265.

15. Fu, Y.; Tiraraghavan, Y. (2004). Removal of Congo red from an aqueous solution by fungus Aspergillus niger. Adv. Environ. Res. 7, 239-247.

16. Glazer, A.N. (1997). Microbial Biotechnology. WH Freeman and Company. New York.

17. Jadhav, J.P.; Govindwar, S.P. (2006). Biotransformation of malachite green by Saccharomyces cerevisiae MTCC 463. Yeast. 23, 315-323.

18. Johnson, R.F.; Zenhausern, A.; Zollinger, H. (1978). Azo dyes. John Wiley and Sons Inc., New York.

19. Kirk, T.K.; Schultz, E.; Connors, W.J.; Lorenz L.F.; Zeikus, J.G. (1978). Influence of culture parameters on lignin metabolism by Phanerochaete chrysosporium. Arch. Microbiol. 117, 227-285.

20. Leisinger, T.; Brunner, W. (1986). Poorly degradable substances. In: Rehm, H.J., Reed, G. (eds). Biotechnology, VCH Verlagsgesellschaft m.b.H., Weinheim, Federal Republic of Germany, 8, p. 475-513.

21. Machado, K.M.G.; Compart, L.C.A.; Morais, R.O.; Rosa L.H.; Santos, M.H. (2006). Biodegradation of reactive textile dyes by basidiomycetes fungi from brazilian ecosystem. Braz. J. Microbiol. 37, 481-487.

22. Meyer, U. (1981). Biodegradation of synthetic organic colorants. FEMS Symp. 12, 371-385.

23. Michaels, G.B.; Lewis, D.L. (1985). Sorption and toxicity of azo and triphenylmethane dyes to aquatic microbial populations. Environ. Toxicol. Chem. 4, 45-50.

24. Michaels, G.B.; Lewis, D.L. (1986). Microbial transformation rates of azo and triphenylmethane dyes. Environ. Toxicol. Chem. 5, 161-166.

25. Milstein, O.; Nicklas, B.; Hutterman, A. (1989). Oxidation of aromatic compounds in organic solvents with laccase from Trametes versicolor. Appl. Microbiol. Biotechnol. 31, 70-74.

26. Niku-Paavola, M.L.; Raaska L.; Itavaara, M. (1990). Detection of white rot fungi by a non-toxic stain. Mycol. Res. 94, 27-31.

27. Pagga, U.; Brown, D. (1986). The degradation of dyestuffs. part II. behaviour of dyestuffs in aerobic biodegradation tests. Chemosphere. 15, 479-491.

28. Parshetti, G.; Kalme, S.; Saratale, G.; Govindwar, S. (2006.) Biodegradation of malachite green by Kocuria rosea MTCC 1532. Acta Chim. Slov. 53, 492-498

29. Pointing, S.B.; Vrijmoed, L.L.P. (2000). Decolourisation of azo and triphenylmethane dyes by Pycnoporus sanguineous producing laccase as the sole phenol oxidase. World J. Microbiol. Biotechnol. 16, 317-318.

30. Rajamohan, N.; Karthikeyan, C. (2006). Kinetic studies of dye effluent degradation by Pseudomonas stutzeri. Available at http://www.ecoweb.com/edi/index.htm Accessed 9 July 2010.

31. Ramya, M.; Anusha, B.; Kalavathy S.; Devilaksmi, S. (2007). Biodecolourisation and biodegradation of reactive blue by Aspergillus sp. Afr. J. Biotechnol. 6, 1441-1445.

32. Ren, S.; Guo, J.; Zeng, G.; Sun, G. (2006). Decolourisation of triphenylmethane, azo and anthraquinone dyes by a newly isolated Aeromonas hydrophila strain. Appl. Microbiol. Biotehnol. 72, 13161321.

33. Sani, R.K.; Azmi, W.; Banerjee, U.C. (1998). Comparison of static and shake culture in the decolourisation of textile dyes and dye stuff by Phanerochaete chrysosporium. Folia Microbiol. 43, 85-88.

34. Sarnthima, R.; Khammuang, S. (2008). Evaluation of dyes decolourisation by the crude enzyme from Pleurotus sajor-caju grown on sorghum seed media. Pak. J. Biol. Sci. 11, 62-67.

35. Slomczynski, D.; Nakas J.P.; Tanenbaum, S.W. (1995). Production and characterization of laccase from Botrytis cinerea 61-34. Appl. Environ. Microbiol. 61, 907-912.

36. Swamy, J.; Ramsay, J.A. (1999). The evaluation of white rot fungi in the decolouration of textile dyes. Enzyme Microb. Technol. 24, 130-137.

37. Thurston, C.F. (1994). The structure and function of fungal laccases. Microbiology. 140, 19-26.

38. Tien, M.; Kirk, T.K. (1983). Lignin-degrading enzyme from the hymenomycete Phanerochaete chrysosporium. Burds. Science. 221, 661 -663 .

39. Van der Zee, F.P. (2002). Anaerobic azo dye reduction. Wageningen, The Netherlands, 142p. (Ph.D. Dissertation. Wageningen University.).

40. Vyas, B.R.M.; Mollitoris, H.P. (1995). Involvement of an extracellular $\mathrm{H}_{2} \mathrm{O}_{2}$-dependent ligninolytic activity of the white rot fungus Pleurotus ostreatus in the decolourisation of remazol brilliant blue R. Appl. Environ. Microbiol. 61, 3919-3927.

41. Yaropolov, A.I.; Skorobogat'ko, O.V.; Vartanov S.S.; Varfolomeyev, S.D. (1994). Laccase: properties, catalytic mechanism, and applicability. Appl. Biochem. Biotechnol. 49, 257-280.

42. Youssef, A.; El-Sherif, S.F.M.; El-Assar, A.S. (2008). Studies on the decolourisation of malachite green by the local isolate Acremonium kiliense. Biotechnology. 7, 213-223.

43. Zimmerinan, T.; Kulla, H.G.; Leisinger, T. (1982). Properties of purified 
orange ii azoreductase, the enzyme initiating azo dye degradation by Pseudomonas KF46. Eur. J. Biochem. 129, 197-203.

44. Zope, V.; Kulkarni, M.; Chavan, M. (2007). Biodegradation of synthetic textile dyes reactive red 195 and reactive green 11 by Aspergillus niger grp: An alternative Approach. J. Sci. Ind. Res. 66 (5), 411- 414. 